Article

\title{
Fringe or Not Fringe? Strategies for Localizing Supported Accommodation in a Post-Deinstitutional Era
}

\author{
Maria Fjellfeldt ${ }^{1, *}$, Ebba Högström ${ }^{2}$, Lina Berglund-Snodgrass ${ }^{2}$ and Urban Markström ${ }^{3}$ \\ ${ }^{1}$ Department of Health and Welfare, Dalarna University, Sweden; E-Mail: mfj@du.se \\ 2 Department of Spatial Planning, Blekinge Institute of Technology, Sweden; E-Mails: ebba.hogstrom@bth.se (E.H.), \\ lina.berglund-snodgrass@bth.se (L.B.-S) \\ ${ }^{3}$ Department of Social Work, Umeå University, Sweden; E-Mail: urban.markstrom@umu.se \\ * Corresponding author
}

Submitted: 30 March 2021 | Accepted: 6 July 2021 | Published: 26 August 2021

\begin{abstract}
Finding suitable locations for supported accommodations is crucial both for the wellbeing of individuals with psychiatric disabilities (PD) and to achieve the objectives of the mental health care reform in order to create opportunities for social inclusion. This article explores municipal strategies for localizing supported accommodations for people with PD. In a multiple case study, interviews with 20 municipal civil servants from social services and urban planning were conducted. Three strategies were identified and further analyzed with a public location theory approach: (1) re-use, i.e., using existing facilities for a new purpose, (2) fill-in, i.e., infilling new purpose-built facilities in existing neighborhoods, and (3) insert, i.e., inserting new premises or facilities as part of a new development. The article shows that the "re-use" strategy was employed primarily for pragmatic reasons, but also because re-using former care facilities was found to cause less conflicts, as residents were supposedly used to neighbors with special needs. When the "fill-in" and "insert" strategies were employed, new accommodations were more often located on the outskirts of neighborhoods. This was a way to balance potential conflicts between residents in ordinary housing and residents in supported accommodations, but also to meet alleged viewpoints of service users' need for a quiet and secluded accommodation. Furthermore, ideas associated with social services' view of social inclusion and urban planning's notion of "tricky" tenants significantly influenced localization strategies. Finally, this article is also a call for more empirical research on the decision-making processes, use of strategies (intended or not) and spatial outcomes, when localizing supported accommodation for people with PD and other groups in need of support and service.
\end{abstract}

\section{Keywords}

municipal localization strategies; psychiatric disabilities; public facility location; social inclusion; supported accommodation

Issue

This article is part of the issue "Home- and Community-Based Work at the Margins of Welfare: Balancing between Disciplinary, Participatory and Caring Approaches" edited by Kirsi Juhila (Tampere University, Finland), Cecilia Hansen Löfstrand (University of Gothenburg, Sweden) and Johanna Ranta (Tampere University, Finland).

(C) 2021 by the authors; licensee Cogitatio (Lisbon, Portugal). This article is licensed under a Creative Commons Attribution 4.0 International License (CC BY).

\section{Introduction}

Mental health care and support provision, in a Global North context, is characterized by a history of treatment, care, management and particular institutional spatial arrangements, often characterized by isolated and relatively sizable asylums facilities (Högström, 2012). Following heavy criticism, a paradigm of protracted deinstitutionalization process in psychiatry began in the later part of the 20th century (Kritsotaki et al., 2016). Instead of providing asylum-based care in isolated settings, the new paradigm advocates care and support in community- 
based settings (Fakhoury \& Priebe, 2007) and, if needed, inpatient care at psychiatric clinics, often located in general hospitals instead of in specialized mental health hospitals (Högström, 2012). In the Swedish context, one policy objective of the mental health care reform was to create preconditions for people with psychiatric disabilities (PD) to have the ability to "participate in society and live like everyone else" (Ministry of Health and Social Affairs, 2001, Chapter 5, Section 7), and to create opportunities for recovery (Government Offices of Sweden, 2012; cf. Slade, 2009). This new mental health care provision paradigm and the contemporary mental health services is to a great extent framed by a "freedom of choice" paradigm (Fjellfeldt, 2017). These emerging trends are referred to as the "post-deinstitutionalization era” (Markström \& Lindqvist, 2015; Rosenberg, 2009). The concept of the post-deinstitutionalization era draws attention to and characterizes the challenges attributed to the "second generation" of community-based mental health services and interconnected spatial arrangements. Here it is generally argued that mental health care systems are slow to change, as they are closely interlinked to local traditions and customs. Services tend to still be delivered in closed settings, and the service delivery organizations struggle to meet the needs of a new generation of users. Swedish policies for a recovery approach to mental health care appear consequently difficult to implement on the local level.

Mental health services in community settings in Sweden are largely organized through two forms of housing and interconnected forms of support depending on need: supported and ordinary housing with outreach services. Approximately one third of people with PD in Sweden live in supported accommodations, making it the cornerstone of Swedish mental health service provision (Tjörnstrand et al., 2020). Although we know a great deal about the characteristics of individual buildings and the perceived quality of service provision from the users and carers perspectives (Eklund et al., 2017; McPherson et al., 2018), we know surprisingly little about the processes of localizing the accommodations in the wider societal context, and whether the locations are supporting the intention of the mental health care reform of creating opportunities for people with PD "to live like everyone else" (Ministry of Health and Social Affairs, 2001). Here we recognize that location and the wider living environment matter for the group's health and wellbeing (Fossey et al., 2020). Therefore, they are a key for successfully implementing the mental health care reform of community-based services, as the location of supported accommodation may operate to support or hinder social integration and social inclusion (Government Offices of Sweden, 2006). By social inclusion we refer to "a desired goal that requires equality of opportunity and participation in the rudimentary and fundamental functions of society" (Rimmerman, 2013, p. 35), whilst recognizing that social inclusion also operates as a moral imperative for which those diagnosed with PD become targets
(Barlott et al., 2020). Such a moral imperative is understood as having both empowering and controlling forces. Striving for inclusion demands adjusting to a majority culture (i.e., the norm), while the mental health service and the spatial arrangements of the supported accommodations simultaneously work to uphold a minority culture of people with PD as "minor" and other than the norm.

There is little research on the processes of locating supported accommodations for people with PD, and the consequences the localization strategies have for goals of social inclusion. A majority of the studies focusing on localization processes were made in the first wave of research on deinstitutionalized mental health care, from the mid-70s to the early 90s, with its home base in the geographical sub-field mental health geography (Wolch \& Philo, 2000). The focus was on spatial-distributional questions, aiming at tracing the shift from large-scale asylums into community-based care, and also, onto the street. For example, Wolpert et al. $(1975$, p. 24) discussed the mental health center as a "noxious facility," needed in neighborhoods but not desired by the residents, and pointed to the fact that there were no specific outlined guidelines for where to locate them. They identified, however, two strategies concerning the actual "siting" of the facilities used to counteract the residents' resistance: (1) a low-profile approach in which communities are educated and coerced into accepting a facility before it was introduced and (2) a "fly-by-night strategy" entailing setting up a facility secretly in the hope that it would not be noticed until its operation could demonstrably be proven to be harmless. Dear (1978) added a third strategy: (3) a risk aversion strategy involving seeking out locations where no community opposition was anticipated or where controversial, "noxious" facilities would go unnoticed, most often in less affluent communities making ideals of social inclusion difficult to achieve. The stigmatization of people with PD is raised as a central component, often called the NIMBY (Not In My Backyard) phenomenon, making it difficult to locate supportive accommodations (Piat, 2000). Dear and Wolch (1987) examined the emergence of "servicedependent ghettos" in the North American context, i.e., the agglomeration of socially dependent people in innercity areas, which was another unexpected "solution" to the problem of developing community-based care for a variety of groups in the early days of deinstitutionalization. More recent research on the topic has reworked the localization of mental health services arguments into wider arguments about the spatial preferences of neoliberal restructurings (cf. DeVerteuil, 2000; Högström, 2018; Lowe \& DeVerteuil, 2020), privatization of medical/care spaces (cf. Hossler, 2012) but also highlighting the benefits of a central location, proximity to nature, transportation, shops and restaurants, according to the service-user themselves (Brolin et al., 2018).

These examples from earlier work around deinstitutionalization makes us curious about the challenges for localizing supported accommodations today. 
Are there stigmatization processes at play when localizing supported accommodations in the Nordic postdeinstitutional landscape? Is the notion of "service dependent ghettos" and "noxious facilities" applicable in the Nordic context, and if so, still valid? Do the strategies for locating the accommodations support social inclusion? These rhetorical questions point to the urgency of moving away from analyzing individual housing in isolation from the context they are situated in (cf. McPherson et al., 2018; Tjörnstrand et al., 2020) and instead emphasizing the overarching strategies for localizing supported accommodations to achieve policy objectives. Our interest is congruent with what Philo $(1997$, p. 78) described as "the complex maneuverings involved as administrators, planners, politicians, community leaders, mental health professionals and facility users argue their way through locational conflicts which are commonly resolved... in favor of powerful and 'respectable' suburban interests."

This article aims to develop a better understanding of municipal strategies for localizing supported accommodations, and whether they support the objectives of social inclusion. A common definition of strategy is a plan, which entails some sort of conscious, intentional course of action to manage a situation (Mintzberg, 1987). However, some strategies appear without preconception, rather they emerge as patterns in a stream of action, as a response to external forces. In this study, we follow Mintzberg's definition and approach strategies as (emergent) patterns. The results stemming from the study have the potential to be directly relevant for policy makers and planning decision-making when planning new supported accommodations. The following research questions organize the study: What municipal strategies characterize processes of localizing supported accommodations for people with PD? What assumptions about people with PD underpin the strategies?

To clarify, the aim of the study is not to examine whether individuals that live in supported accommodations de facto are included in society, but whether the localizing strategies could be understood as supporting the underlying aims of social inclusion. This study is part of a larger research project with the overarching objective of developing knowledge aimed to support socially inclusive living environments for people with PD. The user perspective of the wider living environment of the supported accommodation is subject to analysis in a forthcoming study.

This article is organized in five sections. Following this introduction, which has set out the general research problem, aims and research question, the next section outlines the analytical framework. In the third section, we present the overarching method, procedure for analysis and empirical material. This is followed by a fourth section, an analysis where we identify three different location strategies for supported accommodations: "re-use," "fill-in," and "insert." In the conclusion, we argue that "fillin" and "insert" strategies may result in "fringe localiza- tions," in which the facilities can be said to be integrated in the neighborhoods but in a fringe position. We, furthermore, argue that such "fringe localization" seems to be the result of compromising and negotiating values in planning decision-making, but is not necessarily ideal for creating opportunities for social inclusion for people with PD.

\section{Theoretical Framework}

Public facilities are here understood as "those units whose primary function is to deliver goods and services which fall wholly or partly within the domain of government" (Dear, 1978, p. 94). We adopt this definition by incorporating supported accommodations for people with PD. Our theoretical framework is based on the three dimensions of localizing public facilities outlined in Dear (1978): as access, externalities, and social context, which builds on previous work on public facilities location theory (DeVerteuil, 2000). We agree with Dear's (1978, p. 98) argument that "analysis of the spatial expression of public intervention insists upon a theory of society as well as a theory of space." We would, however, push this towards a clearer relational understanding of the nexus society-space. Here, "space" is not understood as "a container in which things happen, but as a complex mixture of nodes and networks, places and flows, in which multiple relations, activities and values co-exist, interact, combine, conflicts, oppress and generate creative synergy" (Healey, 2007, p. 1). When Dear (1978, p. 98) claims that there is "a direct correlation between social policy and spatial outcome," we would see this in a relational perspective, as even though the spatial aspects are in many respects "outcomes" of social processes, social conditions will also emerge out of spatial arrangements.

In analyzing the strategies for localization with help of the three dimensions mentioned above, we approach "localization" as producing different forms of (1) accessas availability of services, social encounters, cultural experiences, etc., but also as the enabling factor public transportation or other mobility measures have for accessing those-and (2) externality-the impact or external effects on the "users" (i.e., the mental health service users) and "non-users" (i.e., neighbors) produced by the localization process. These are divided into userassociated externalities and neighborhood-associated externalities in the host community, and could be tangible (e.g., more traffic) or intangible (e.g., fear). The third approach as outlined by Dear (1978) refers to localization decisions in the context of the wider socio-economic and political formation which place mental health services and spatial considerations right into the socio-political context. A wide range of factors act in relation to each other, for example, ideas of independence and civil liberty, planning and land-use policies, fiscal values and cost savings, welfare state restructuring, as well as conceptions molded throughout history (e.g., stigma and 
other exclusionary discourses related to people with PD). We define this third approach as (3) the social context, including spatial circumstances, socio-political considerations and other conditions underpinning localization decision-making.

This study is situated within the post-deinstitutional era characterized by the recovery paradigm (Slade, 2009). In a recovery oriented mental health service perspective, access to areas supporting personal development, close relationships and peer-relationships, as well as areas promoting well-being, should be taken into consideration when locating an accommodation for people with PD. In the recovery perspective, access to a social environment where people can develop valued social roles, and areas where they can develop a positive identity by experiencing identity-enhancing relationships, should be considered. We will analyze the localization dimensions in light of the relevance for recovery for persons with PD, which means we will focus on the wider community mental health setting as well as the more detailed spatial arrangements.

\section{Methods and Data}

The research is a Swedish multiple case study (Yin, 2014) of municipal processes of localizing supported accommodations in built up areas. The objective for conducting a multiple case study was to develop a broader understanding of strategies that are employed for localizing supported accommodations across different cases, and not only from one single case. We selected the typical and average cases (cf. Flyvbjerg, 2007) for localizing supported accommodations in Sweden. These cases are not presented as particularly successful, "good" or extreme. Five cases were chosen to represent typical localization processes in Swedish municipalities of different sizes, in diverse parts of the country. Our selection is based on a national compilation (Swedish Association of Local Authorities and Regions, 2016) which divides municipalities into categories according to size and character (Table 1). We have also strived for a balanced geographical mix in the selection.

\subsection{Empirical Material}

In each case, key stakeholders involved in processess of localizing supported accommodations for people with PD have been interviewed. This includes urban planners, social service strategists and heads of administration. Altogether twenty $(N=20)$ semi structured, faceto-face interviews were conducted (cf. Brinkmann \& Kvale, 2018). The interviews were carried out between February 2019 and February 2020, each interview was 30-45 minutes long, recorded and transcribed verbatim. The principles of informed content, voluntary participation and confidentiality were applied. In the interviews, we asked questions such as: How are processes of locating supported accommodations carried out? What actors are involved? Were any difficulties encountered in the process? To what extent were the users involved?

In addition to the interviews, detailed development plans and site plans, showing proposed urban development were included in three cases in which new buildings were either recently built or planned for in the near future (cases 2, 3 and 4). In one of these cases, a planning document that describes the local environment was included (case 4). In the two other cases (cases 1 and 5), new buildings were not scheduled within the timeframe of the current study period.

\subsection{Empirical Context of Locating Supported Accommodations}

Localizing supported accommodations is in Sweden a municipal endeavor, and engages a range of different professionals, especially urban planners, social strategists and public facilities strategists. The activities are regulated by the Swedish Planning and Building Act (Ministry of Finance, 2010) that stipulates that any planning or development should be pursued with the overarching ethic of the public interest. The activities are furthermore regulated by the Social Service Act (Ministry of Health and Social Affairs, 2001) which stipulates that the municipality should provide "adapted" accommodation in ordinary housing, or supported accommodation, to people encountering significant difficulties in their lives

Table 1. Size, character and geographical location of the municipalities of the cases.

\begin{tabular}{llll}
\hline $\begin{array}{l}\text { Municipal processes of localizing } \\
\text { supported accommodation }\end{array}$ & Character of the municipality & Population & Geographical location in Sweden \\
\hline Case 1 & small city & 64000 & South \\
Case 2 & $\begin{array}{l}\text { commuting municipality close } \\
\text { to a medium-sized city }\end{array}$ & 11000 & Mid \\
Case 3 & small city & 57000 & Mid-north \\
Case 4 & part of a metropolitan area & 96000 & Mid \\
Case 5 & commuting municipality close & 15000 & South \\
& to a smaller city & & \\
\hline
\end{tabular}


due to mental reasons. Since the deinstitutionalization of mental health care in Sweden in the late 1980s, social inclusion of people with PD has been a guiding norm of social services provided (Ministry of Health and Social Affairs, 2001).

\subsection{Analytical Procedure}

The initial analytical procedures resulted in themes based on the civil servants' experiences, ideas and values concerning municipal processes for locating supported accommodations (Clarke, 2003). At this first stage, three empirical strategies that we label as "re-use," "fill-in," and "insert" were identified. Enabling an in-depth analysis in a second stage, the analytical framework of three dimensions of localizing public facilities was applied (Hsieh \& Shannon, 2005). The analysis was conducted by the four authors in a collaborative manner, which included a continuous discussion across disciplinary boundaries of social work and urban planning.

\section{Municipal Strategies for Localizing Supported Accommodations}

This section presents the results of the analysis, with the three strategies for locating supported accommodations ("re-use," "fill-in," and "insert") and how they are reflected in our five cases and analyzed by using the lens of localization of access, externalities and social context.

\subsection{Re-Use: Using Existing Buildings for New Purposes}

The "re-use" strategy was prevalent in all five cases and is characterized by re-using existing buildings for new mental health services purposes. The buildings subject to re-using had previously been used as residential homes (e.g., as refugee accommodations or nursing homes). One significant consequence of this strategy is that the accommodations are not purposely designed for mental health services, rather for people needing social services generally. One social service civil servant states:

The old accommodations were never initially intended as supported accommodations. I think it was a senior retirement home from the start, which was displaced to another location.... So, it was nothing more, a vacant space. We take it. (case 3, social services)
The existing buildings in our cases were located in neighborhoods with a long tradition of accommodating people in need of societal support. The "re-use" strategy had been used for decades and was viewed by the social service civil servants as a pragmatic solution.

In terms of access, the existing buildings, referred to in the cases, were located in established neighborhoods well serviced with public transportation. The buildings were described by the interviewees to often be centrally located in the neighborhoods, providing the residents easy access to various services, sport activities and grocery stores. Having access to public transportation was raised as an overarching concern among the social service civil servants in all cases since they recognized that the mental health service users often lacked a driver's license.

Concerning externality, the "re-use" strategy could be considered in a twofold respect. On the one hand, the social service civil servants experienced the relationship between the accommodation and the neighborhood where it was located as unproblematic. The latter was described by a social service official in case 5 as a community where human differences were understood and tolerated. On the other hand, user-associated externalities occurred, as some social service civil servants underlined the importance of ensuring resident anonymity regarding their home and ensuring the accommodation would not stand out in the neighborhood when they advocated for a "blend-in" architecture. This idea was, however, not supported by letting mental health service users move into buildings with a history as public facilities, as in case 3, a former elder care home.

When it comes to the social context, civil servants in social service in cases 1, 3 and 5 used such expressions as "you take what you get" when describing the "re-use" strategy, often referring to a general shortage of suitable housing and buildings and, as such, relating to a wider social and political context. To be able to meet the requirement to provide housing to persons belonging to the target group in the near future, this strategy was experienced by the social service civil servants as a pragmatic solution. There seemed to be no particular social ideas of inclusion and recovery, nor urban planning ideas of densification or sociable living environment space underpinning this strategy. Providing accommodations with a reasonable standard of living according to the Social Service Act appears as a difficult enough goal to accomplish.

Table 2. An overview of the incidence of the strategies in the five cases.

\begin{tabular}{lccc}
\hline & Re-use strategy & Fill-in strategy & Insert strategy \\
\hline Case 1 & $\mathrm{X}$ & $\mathrm{X}$ & $\mathrm{X}$ \\
Case 2 & $\mathrm{X}$ & & $\mathrm{X}$ \\
Case 3 & $\mathrm{X}$ & $\mathrm{X}$ \\
Case 4 & $\mathrm{X}$ & \\
Case 5 & $\mathrm{X}$ & & \\
\hline
\end{tabular}




\subsection{Fill-In: Purpose-Built Supported Accommodations in Existing Neighborhoods}

The "fill-in" strategy that was used in one of the cases (case 2) concerned allocating land for purpose-built supported accommodations in already built-up neighborhoods. The new accommodations were planned to be located on existing park or woodlands in the outskirts of the neighborhood. This strategy is characterized by being conflictual and time consuming (e.g., years) due to the many protests during the planning process. Similar experiences of time-consuming processes led municipalities in the other cases to abandon this strategy. In case 2, in which the strategy (still) was prevalent, the municipality was confronted with a situation in which one existing supported accommodation was assessed as inadequate and inappropriate by the Health and Social Care Inspectorate as it was seen as too institutional-like. As a result, the municipality planned to localize a new purpose-built accommodation in an existing neighborhood. The accommodation was initially planned to be localized in a central part, but the municipality was forced to change the location to another neighborhood due to complaints. The social service civil servants stressed in the interviews that no final political decision about the localization for the supported accommodation has yet been made.

Concerning access, the "fill-in" strategy meant that the new supported accommodation was to be sited between two neighborhoods (case 2). This signified mental health service users were to be living in between two already established neighborhoods and set up ser- vices, such as public transportation. In a first stage of the localization process, access was fully considered by the informants when the accommodation was planned to be localized in a park area close to the city center. However, neighbors appealed the localization and the municipality had to find another site for the accommodation. The future residents' access to various services providing arenas for recovery (e.g., social environments and identity-enhancing relationships) was not prioritized when the new localization was decided. The supported accommodation will be built between two existing neighborhoods and is furthest to the center of the two (Figure 1). In the immediate vicinity of the site, a road, a park and two residential houses are located. We characterize this as an example of a "fringe localization" (i.e., accomodations located at the edge of a neighborhood, next to parks or other public facilities).

Case 2 shows clearly how dimensions of localization as externality were played out. The process of building the new supported accommodation was abruptly aborted owing to objections from neighboring property owners, forcing the municipality to continue providing supported accommodation in the inadequate and inappropriate facilities. According to the informants, the reason for objecting was that the new accommodation presented a perceived threat to the residents in the neighborhood. One informant described the complaints as "these people can be dangerous; we cannot let our children out. So, there is a lot of lack of knowledge and prejudice. I would say that it is mostly about lack of knowledge" (case 2, manager, social services).

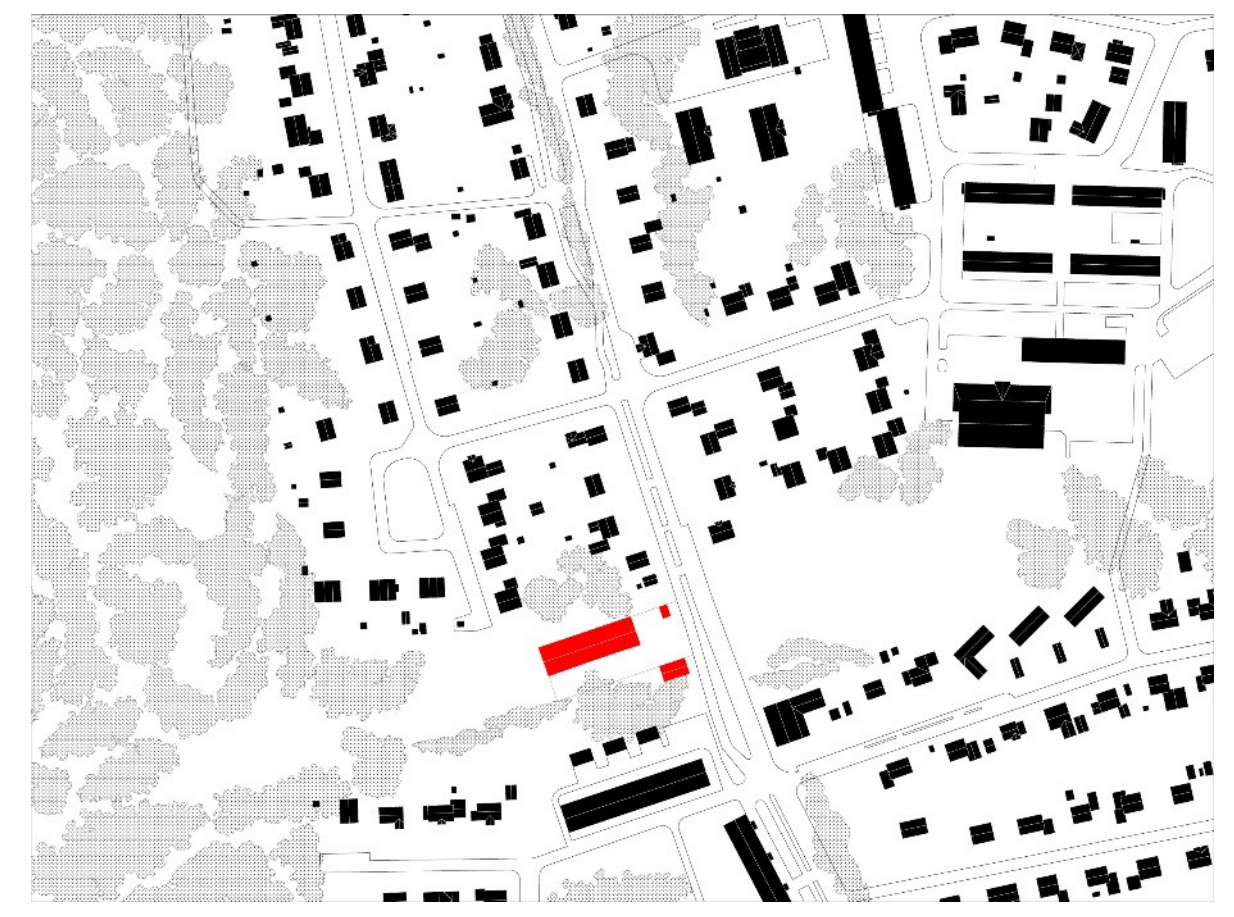

Figure 1. Fringe localization I. This figure shows the site plan over the planned accommodation of case 2. The localization is in between two existing neighborhoods surrounded by a road, a park and two residential houses. Drawing by Andrea Gimeno Sanchez. 
The social service civil servants interpreted the threat as baseless, relating it instead to ignorance and lack of knowledge. In this case, one user-associated intangible external effect was the experience of an awareness of a prejudiced context in the local community, i.e., neighbors oppose the accommodation. Another userassociated external effect associated with the "fill-in" strategy, but a tangible one, was that residents were forced to continue to live in their inadequate and inappropriate facilities for an uncertain amount of time.

In terms of social context, the case illustrates the municipal urban planning civil servants striving to balance between different public and private rights and needs. There was a conflict between on the one hand individuals with rights as residential stakeholders and, on the other hand, the society's task to cater for those in need of societal support. The different positions adopted by the municipal urban planning and social service civil servants were set against each other. One pragmatic view was expressed by the city architect. When the planned supported accommodation was stopped, this architect's new idea consisted of locating it in the woodlands where neighbors most likely would not object. Other social service and urban planning civil servants involved, however, did not approve of this proposal, according to the prevailing idea of integration and inclusion. Instead, the "fill-in" strategy was used again. Another neighborhood was selected for the new accommodation, and for planning and dealing with the existing residents' opinions. An urban planning ideal of densification admittedly prevailed but was balanced with the view of mental health service users as a homogenous group with a need for privacy and shelter.

\subsection{Insert: Purpose-Built Accommodations in New Developments}

Planning new facilities as part of a larger new development was a long-term strategy used in cases 1, 3 and 4. This "insert" strategy involves allocating plots dedicated to the social service to suit their land allocation needs, as well as regulating land use, and cooperation between social services and urban planning was essential. However, the "insert" strategy was also a complex and time-consuming process. The process to leave the old accommodation in case 4 and move into something more appropriate had taken about 8 years. The actual move into the new facilities was expected to take place in another 3 years. When inserting supported accommodations in new developments, informants referred to the National Board of Housing, Building and Planning, advising how many residents they should include and where to locate them, to avoid an excessive number of similar accommodations in the same area.

When studying the detailed plans, the new supported accommodations were located at the edge of the new development, which we characterize as another example of a "fringe localization." This could imply people living in the accommodation would get almost the same access to social environments, opportunities for identity-enhancing relationships and to public transportation as other residents in the neighborhood. The residents of the supported accommodation live in the neighborhood, but furthest from its center. The supported accommodation in case 3, inaugurated in 2018 as a result of the "insert" strategy is located at the very edge of the neighborhood with no residential housing next door and surrounded by walking paths, a road and a preschool (Figure 2).

Concerning externality, the social services raise the importance of regulating land use for care purposes in the early stage of the detail planning process (i.e., in the terms used in detail planning social services facilities are incorporated in the term "care"):

It is very important, as I said, when you make a detailed plan that, from the beginning, to state the "care purpose" because then it is there. Then you [neighbors] can never oppose it-it's, like, the point. Then maybe we do not [use all]. If we say it is in ten places, we will perhaps only construct five. But there is a possibility. And they always write housing, $\mathrm{H}$ or $\mathrm{C}$, housing or care [in the detail plan]. But if we then say no, it is not relevant because we have no need. Then, it can be ordinary housing instead. It is important to have this flexibility, so we are included in the new ones. And it has been missing in the old, detailed plans, so there are huge problems with the old existing ones. (case 1 , social strategist)

Using the "insert" strategy, location as an externality from a mental health service user perspective could differ from the user-associated perspective in the "fill-in" strategy presented in the previous section. Here, people who chose to live in this new development were possibly already aware of the planned supported accommodation. They could be expected not to oppose their future neighbors given that they were mindful in advance of the planned insertion of a public facility in the new development. When regulating land use for care purposes as in this case, it is anticipated that fewer objections from stakeholders will be made in the development phase.

The social context in which the "insert" strategy emerged was to a great extent characterized by the prevailing urban planning ideas of densification. In this case 4 , the supported accommodation would comprise two floors in a planned construction of a larger residential block (Figure 3):

It [accommodation] will be integrated into a larger property. They have sketched a house, I think, five floors high.... do not see that a detached building is needed. I mean ten apartments and common and staff spaces-it will be quite large. It makes a very large footprint on land, so I think it is an advantage that it is integrated. (case 4 , social strategist) 


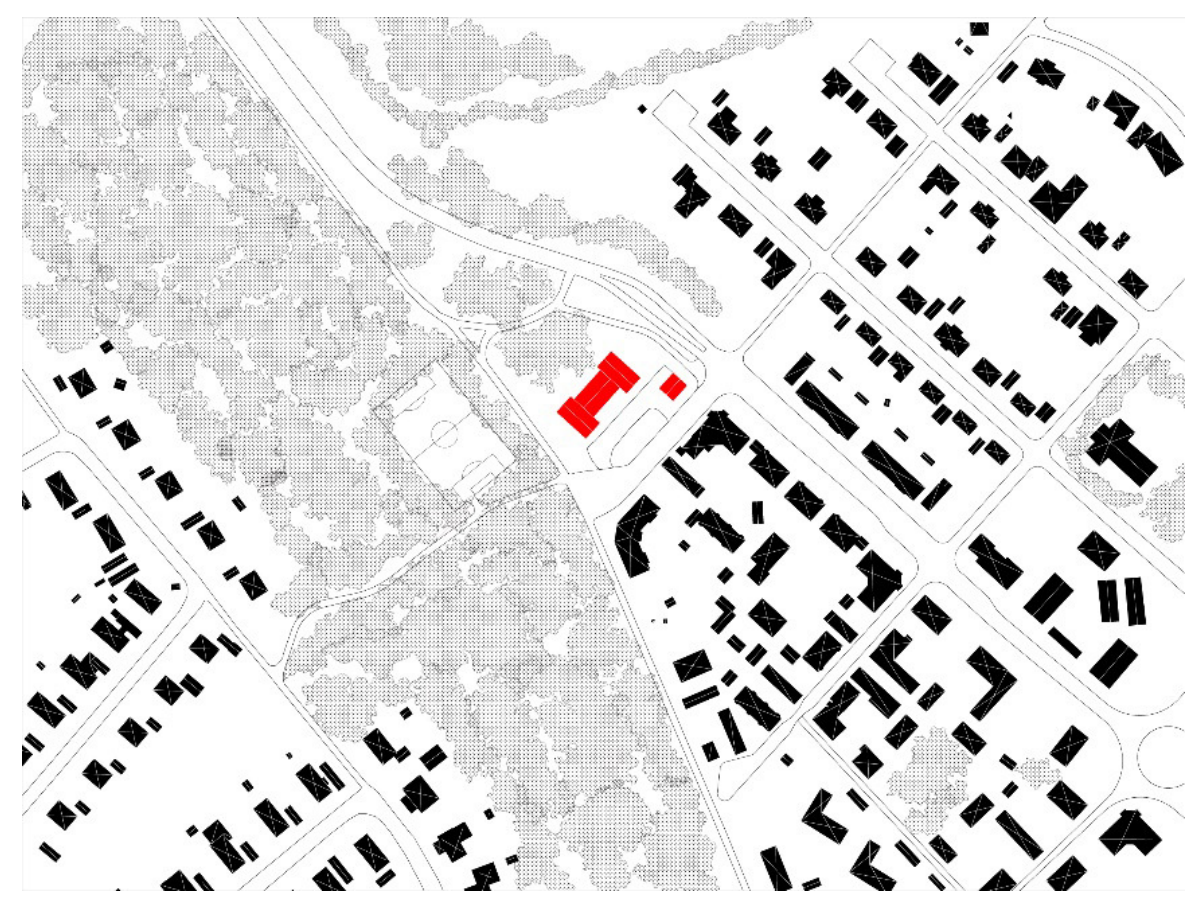

Figure 2. Fringe localization II. This figure shows the localization of the supported accommodation of case 3 . Here the "insert" strategy was applied, i.e., the supported accommodation as part of a new urban development but as a freestanding construction. Drawing by Andrea Gimeno Sanchez.

The "insert" strategy was viewed by the social service as well as urban planning civil servants as an appropriate and efficient way of using land, supporting the idea of densification of sub-urban areas but also in line with ideas of localizing supported accommodations in neighborhoods as a way to support inclusion (i.e., following the ideal of community support and service). The social strategist also said: "I really work for all people, regardless of disability or age, to be together. I think that is a matter of course" (case 4 , social strategist).

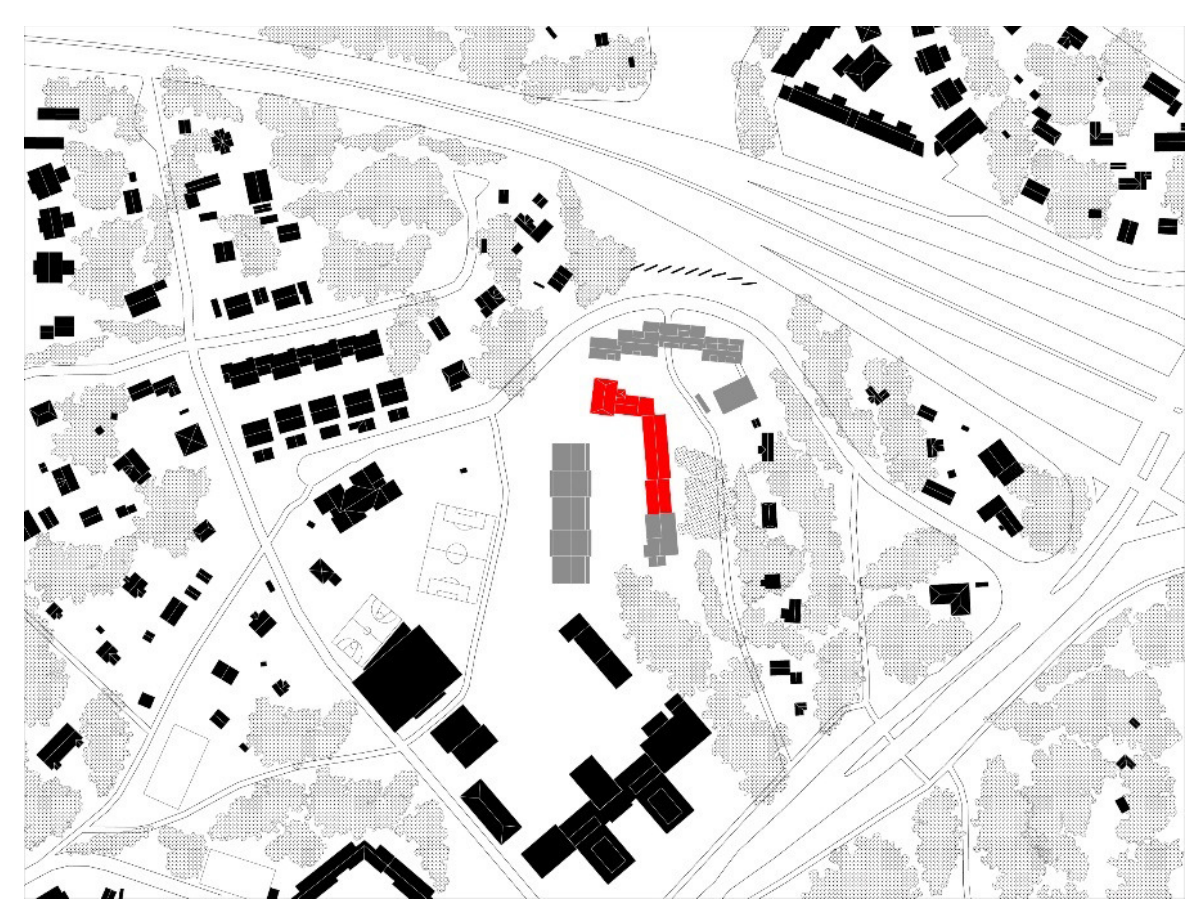

Figure 3. Fringe localization III. This figure shows the site plan for the new development, where the supported accommodation of case 4 will be inserted. The "insert" strategy was applied, i.e., the accommodation will form a part of the new development comprising mainly housing. The site is circumscribed by a regional motorway, a local road with quite high traffic loads, and education and sports facilities. Drawing by Andrea Gimeno Sanchez. 
This quote illustrates social service civil servants' underlying assumptions, namely perceiving users as a heterogeneous group of citizens with the same rights and needs as any other person, where social inclusion and integrated living were advocated. This viewpoint is in line with the contemporary social policy of recovery, and in direct opposition to historical perceptions of people with PD to a great extent distinguished by stigmatization, prejudices and paternalistic logics. According to the social service civil servants representing this view, the localization's access to public transportation was of utmost importance (e.g., to be able to attend activities which make you feel better). Public transportation is here a measure to reach the overarching goal of social inclusion.

Another view challenged the above mentioned understanding of the group as heterogeneous. This view sees the target group as primarily vulnerable with special needs. Consequently, a localization in a more private and calm area was suggested. In case 4 , in which the social service strategist advocated integration, a colleague from the urban planning department expressed another view:

They [accommodations] can sometimes not be integrated into an ordinary housing stock but have to be a little more at the side because tenants are a little tricky. You want to give them space while also reducing potential friction with other people. And we also need to think strategically. Is it the case that we have some places we can use that are strategically located but perhaps not exactly in a large housing stock? (case 4, urban planning)

The "insert" strategy revealed a close collaboration between social services and urban planning when analyzing the spatial processes and their underlying ideas and values. In this collaboration (case 4) the different opinions and views of the target group and their living environments were subject to negotiation. For example, civil servants from social services advocated integration, whereas those from urban planning recommended privacy and shelter. The latter might be mirroring a lack of knowledge in the recovery paradigm of the importance of a wider repertoire of social relations and arenas. The negotiations between the two groups of civil servants resulted in a localization of the new accommodation in the periphery of the neighborhood, but inserted in a residential building (e.g., mental health service users were included but at the very edge). The planning document description recounts the area in which the new supported accommodation in case 4 is to be built as follows:

The area has not been planned earlier... and is located in the eastern part of $X$ between the highway and $Z$ school. Today, there is an apartment complex and a social service facility belonging to the municipality, two private residential buildings, currently empty, a nature area with valuable trees, a network station and two municipal roads. The plan proposals allow for about 50 new homes on private land and about 70 new homes (rental apartments) on municipal land. Within the area of the municipal owned land, about 10 apartments will also be created for people with psychiatric disabilities. The homes [for people with PD] will be integrated into the apartment building. (case 4, planning document)

This description together with the site plan (see Figure 3) describes in text and in visuals how the accommodation is located in the fringe of the sub-urban area, and it is another example of a "fringe localization." This localization was designed to balance conflicts between residents in ordinary housing and residents in supported accommodations.

\section{Discussion and Conclusions}

There is a scarcity of contemporary research which focuses on the processes of localizing supported accommodations for people with PD, and the consequences the localization strategies have for goals of social inclusion. This article has looked into overarching strategies for localizing supported accommodations to achieve policy objectives, rather than analyzing individual housing, more or less in isolation from the context they are situated in (cf. McPherson et al., 2018; Tjörnstrand et al., 2020). In this article, we have sought to develop a better understanding of the ways in which municipal strategies for locating supported accommodations are composed, and whether these strategies work to support the objectives of social inclusion.

The study identified three localizing strategiesemerged as patterns out of action rather than out of preformulated intentions (Mintzberg, 1987): (1) "re-use," i.e., using existing buildings for new purposes, (2) "fill-in," i.e., purpose-built accommodations in existing neighborhoods, and (3) "insert," i.e., inserting purpose-built accommodations in a new urban development. We analyzed these strategies with the help of three dimensions of localizing public facilities, i.e., as access, externalities and social context. A relational space dimension was added as well as an attention to the recovery paradigm (cf. Dear, 1978; Healey, 2007; Slade, 2009).

This study demonstrates that in all of our five cases, the idea of integration in the local community seemed to prevail across the two municipal administrations of social service and urban planning. New buildings for supported accommodation and other mental health service facilities were never planned outside the built-up areas of the neighborhood, as was the predominant norm during the asylum era right up until the mid-20th century (Högström, 2012). In the post-deinstitutional era mental health service facilities in general are more often integrated in the local neighborhoods to support the idea of being part of a community. However, we have shown that at the local scale the idea of integration 
was compromised by actual localizations in the outskirts of neighborhoods, i.e., the spatial arrangement at the fringe impacted the social process.

The question whether identified strategies support objectives of social inclusion was, however, understood in a nuanced and multifaceted way by the informants. "Fill-in" and "insert" strategies implied community mental health service users lived in a kind of "spatial trade-off" in which urban planning and social services meet. Such accommodations are integrated but sheltered, with few neighbors that could negatively impact the residents living conditions. While residents are exposed to society and live as others to some extent, they are also sheltered in order not to disturb others or experience conflict with neighbors. Still, according to these two strategies, service users should also be included in society and live like others in the community. Social policies and spatial processes are related and influence each other, sometimes the latter is an outcome of the former (Dear, 1978) and sometimes more complex maneuverings take place, not only among civil servants and other agents but also in how spatial arrangements impact on the emergent strategies and on the everyday life of people with PD (Healey, 2007; Philo, 1997). Concerning social inclusion (Rimmerman, 2013), residents are both socially included and excluded, or neither socially included nor excluded, depending on the perspective taken.

Another example of the relational link between social policy and spatial processes (Dear, 1978; Healey, 2007), and of localization as social context was that informants referred to the National Board of Housing, Building and Planning advising how many residents a supported accommodation should have and where to locate them to avoid aggregations in the same area. Accordingly, national advisories determined how the post-deinstitutional community mental health service landscape should develop. The approach was not to have too many mental health service users in the same accommodation, nor to include too many special accommodations at the same place. This contemporary way of regulating the emergence of what Wolpert et al. (1975) in the 70s called "service-dependent ghettos" could be understood as a form of government control in the name of social inclusion, where the majority constitute the normal society in which the minority-those with PDbecome targets for social inclusion (Barlott et al., 2020)

The major/minor tension was visible when using the "re-use" strategy. The history of the reused building could entail a risk for experiences, among service users as well as other residents in the neighborhood, of situations where a norm, the major, in this case "host" community meet those outside the norm, the minor, in this case supported accommodation residents (Barlott et al., 2020). At the same time, when using the "re-use" strategy, in terms of localization as access, residents could be understood as being provided with access to social environments and arenas in which they could develop valuable roles and positive identities through identity- enhancing relationships (Slade, 2009) supporting the recovery objective in national policies in another way than when using strategies "fill-in" and "insert."

When using strategy "fill-in" and "insert," the social services' notion of social inclusion and urban planning's concept of "tricky" tenants significantly impacted where new accommodations were localized. When combining these ideas, the new accommodations were often situated in the outskirts of urban areas, in between neighborhoods or at the border to woodlands, sport facilities and/or roads. We suggest this process as an example of a "fringe localization." This type of localization as social context was to a great extent imposed as a pragmatic way to balance potential conflicts between residents in ordinary housing and residents in supported accommodations, and consequently as an example of what Wolpert et al. (1975) called "risk aversion."

What social implications does the "fringe localization" phenomenon generate for the community mental health services? Previous research shows that friendly neighborhood interactions and meaningful places (i.e., places persons are attached to and important for individual wellbeing) are valuable to improve the situation and health of persons with PD (Fossey et al., 2020). The question is how these aspects are played out in "fringe localizations" and how these strategies support the access to components of a recovery oriented mental health service supply. Here, we refer to social environments where one could develop valued social roles and a positive identity, and arenas where close relationships could be established (Slade, 2009). When using the "fill-in" strategy from a service-user perspective, location as an externality implies winding up in an area where residents oppose spatial change. The appeal process entails knowledge among service users that one or more persons do not want you as a neighbor. The "re-use" strategy and "insert" strategy seemed to facilitate supporting friendly neighborhood interactions (Fossey et al., 2020) in another way than in the "fill-in" strategy, as future neighbors are more aware of each other. However, as a mental health service user, to be located in the margin, in the "fringe," next to parks, main roads or preschools, does not seem to have the best potential to support social inclusion in the community.

The finding that access to public transport was an overriding issue across the strategies because the target group often lacked a driver's license is related to dimensions of social inclusion highlighted in mental health research, stating that social inclusion is "a desired goal that requires equality of opportunity and participation in the rudimentary and fundamental functions of society" (Rimmerman, 2013, p. 35). Consequently, accessible public transport is a necessary condition to enable social inclusion.

To conclude, the results showed that municipalities, both large and small, seemed to face very similar challenges in the municipal localization processes. Our conclusion is that there was not a single overarching idea 
guiding these processes, but rather a combination of various ideas, values and conditions that municipal civil servants in urban planning and social service balanced, e.g., between an urban densification ideal, demands on maximizing land use, a recycling trend, housing shortage, as well as private (neighbors) and public (accommodations) interests. The results further suggests that in the post-deinstitutional era, the "insert" strategy can be considered as a way to preclude the NIMBY phenomenon (Piat, 2000) emerging, and the strategy could be understood as an example of the "risk aversion" approach used during the early deinstitutionalization process (Dear, 1978). The "insert" strategy includes identifying locations in which no community opposition is anticipated. Additionally, one new labelling could be added in the post-deinstitutional era, based on the "re-use" strategy: a "familiar-with" approach, where buildings already serving and identified by the community as welfare buildings of some kind were re-used for mental health service purposes. The other two localization strategies, as captured by Wolpert et al. (1975) in the early deinstitutionalization era, the "low profile" and the "fly-by-night" strategies, were not identified in the five cases included in this study.

Finally, this study indicates the need for further research concerning mental health service users' subjective experiences of supported accommodation localization, in terms of how it impacts their lives, in what way localizations support social inclusion and personal recovery processes, but also if these accommodations could be included in its own right in urban development visions. This article is also a call for rethinking public facility location theory through more empirical research on the decision-making and participatory processes, use of strategies (intended or not) and the spatial outcomes, when localizing supported accommodation for people with PD and other groups in need of support and service. Finally, the policy of social inclusion (Government Offices of Sweden, 2006) points directly into the ardent political question of housing shortage and how to provide vulnerable and low-income groups (in which people with PD are included) affordable and appropriate dwellings (see, for example, Berglund-Snodgrass et al., 2021). This relates to broader questions concerning social sustainability (Dempsey et al., 2011), including equal access to shared resources, community resilience and to the simple but nevertheless crucial question: How do we want to live together?

\section{Acknowledgments}

The authors would like to thank Kitty Lassinannti and Anna-Lena Almqvist, as well as the three anonymous reviewers, for their valuable comments and suggestions on earlier drafts of the manuscript. We also would like to thank Andrea Gimeno Sanchez for providing the illustrations. We also thank Charles Snodgrass for excellent proofreading. This research project was funded by Formas-Swedish Research Council for Sustainable Development (2018-00058 and 2018-00192) and ForteSwedish Research Council for Health, Working Life and Welfare (2018-01325).

\section{Conflict of Interests}

The authors declare no conflict of interests.

\section{References}

Barlott, T., Shevellar, L., Turpin, M., \& Setchell, J. (2020). Destabilizing social inclusion and recovery, and pursuing 'lines of flight' in the mental health sector. Sociology of Health \& Illness, 42(6), 1328-1343. https://doi.org/10.1111/1467-9566.13106

Berglund-Snodgrass, L., Högström, E., Fjellfeldt, M., \& Markström, U. (2021). Organizing cross-sectoral housing provision planning: Settings, problems and knowledge. European Planning Studies, 29(5), 862-882. https://doi.org/10.1080/09654313.2020. 1792416

Brinkmann, S., \& Kvale, S. (2018). Doing interviews. SAGE. Brolin, R., Syrén, S., Rask, M., Sandgren, A., \& Brunt, D. (2018). Residents' perceptions of the most positive and negative aspects of the housing situation for people with psychiatric disabilities. Scandinavian Journal of Caring Sciences, 32(2), 603-611.

Clarke, A. E. (2003). Situational analyses: Grounded theory mapping after the postmodern turn. Symbolic Interaction, 26(4), 553-576. https://doi.org/ 10.1525/si.2003.26.4.553

Dear, M. (1978). Planning for mental health care: A reconsideration of public facility location theory. International Regional Science Review, 3(2), 93-111. https:// doi.org/10.1177/016001767800300201

Dear, M., \& Wolch, J. (1987). Landscapes of despair: From deinstitutionalisation to homelessness. Oxford University Press.

Dempsey, N., Bramley, G., Power, S., \& Brown, C. (2011). The social dimension of sustainable development: Defining urban social sustainability. Sustainable Development, 19(5), 289-300.

DeVerteuil, G. (2000). Reconsidering the legacy of urban public facility location theory in human geography. Progress in Human Geography, 24(1), 47-69. https:// doi.org/10.1191/030913200668094045

Eklund, M., Argentzell, E., Bejerholm, U., Tjörnstrand, C., \& Brunt, D. (2017). Wellbeing, activity and housing satisfaction-Comparing residents with psychiatric disabilities in supported housing and ordinary housing with support. BMC Psychiatry, 17(1), 315-315. https://doi.org/10.1186/s12888-017-1472-2

Fakhoury, W., \& Priebe, S. (2007). Deinstitutionalization and reinstitutionalization: Major changes in the provision of mental healthcare. Psychiatry, 6(8), 313-316. https://doi.org/10.1016/j.mppsy.2007.05. 008 
Fjellfeldt, M. (2017). Choice as governance in community mental health services [Doctoral dissertation, Umeå University]. UmU Print Service.

Flyvbjerg, B. (2007). Five misunderstandings about casestudy research. In C. Seale, G. Gobo, J. Gubrium, \& D. Silverman (Eds.), Qualitative research practice (pp. 390-404). SAGE.

Fossey, E., Harvey, C., \& McDermott, F. (2020). Housing and support narratives of people experiencing mental health issues. Frontiers in Psychiatry, 10, 939-939. https://doi.org/10.3389/fpsyt.2019.00939

Government Offices of Sweden. (2006). Ambition och ansvar: Nationell strategi för utveckling av samhällets insatser till personer med psykiska sjukdomar och funktionshinder [Ambition and responsibility: National strategy for the development of welfare services aimed at people with mental illness and disability. Official reports of the Swedish Government] (SOU 2006:100). Fritze.

Government Offices of Sweden. (2012). PRIO psykisk ohälsa-Plan för riktade insatser inom området psykisk ohälsa 2012-2016 [PRIORITY mental illnessPlan for targeted interventions in the field of mental ill health from 2012-2016]. Ministry of Health and Social Affairs.

Healey, P. (2007). Urban complexity and spatial strategies: Towards a relational planning for our times. Routledge.

Högström, E. (2012). Kalejdoskopiska rum: Diskurs, materialitet och praktik i den decentraliserade psykiatriska vården [Kaleidoscopic spaces: Discourse, materialty and practice in decentralised mental health care; Doctoral dissertation, Royal Institure of Technology]. AJ E-print AB.

Högström, E. (2018). 'It used to be here but moved somewhere else': Post-asylum spatialisations-A new urban frontier? Social \& Cultural Geography, 19(3), 314-335. https://doi.org/10.1080/14649365.2016. 1239753

Hossler, P. (2012). The privatization of the Milwaukee clinical campus. Geoforum, 49, 81-90. https://doi. org/10.1016/j.geoforum.2013.05.013

Hsieh, H.-F., \& Shannon, S. (2005). Three approaches to qualitative content analysis. Qualitative Health Research, 15(9), 1277-1288. https://doi.org/ $10.1177 / 1049732305276687$

Kritsotaki, D., Long, V., \& Smith, S. (Eds.). (2016). Deinstitutionalisation and after: Post-war psychiatry in the western world. Palgrave Macmillan.

Lowe, J., \& DeVerteuil, G. (2020). Power, powerlessness and the politics of mobility: Reconsidering mental health geographies. Social Science \& Medicine, 5(252). https://doi.org/10.1016/j.socscimed.2020. 112918

Markström, U., \& Lindqvist, R. (2015). Establishment of community mental health systems in a post- deinstitutional era: A study of organisational structures and service provision in Sweden. Journal of Social Work in Disability and Rehabilitation, 14(2), 124-144.

McPherson, P., Krotofil, J., \& Killaspy, H. (2018). Mental health supported accommodation services: A systematic review of mental health and psychosocial outcomes. BMC Psychiatry, 18(1), 128-128. https://doi. org/10.1186/s12888-018-1725-8

Ministry of Finance. (2010). Plan och bygglagen [Planning and Building Act] (SFS 2010:900).

Ministry of Health and Social Affairs. (2001). Socialtjänstlagen [Social Service Act] (SFS 2001:453).

Mintzberg, H. (1987). The strategy concept I: Five Ps for strategy. California Management Review, 30(1), 11-24. https://doi.org/10.2307/41165263

Philo, C. (1997). Across the water: Reviewing geographical studies of asylums and other mental health facilities. Health \& Place, 3(2), 73-89. https://doi.org/ 10.1016/S1353-8292(97)00002-6

Piat, M. (2000). The NIMBY phenomenon: Community residents' concerns about housing for deinstitutionalized people. Health \& Social Work, 25(2), 127-138. https://doi.org/10.1093/hsw/25.2.127

Rimmerman, A. (2013). Social inclusion of people with disabilities: National and international perspectives. Cambridge University Press. https://doi.org/ 10.1017/CBO9781139035668

Rosenberg, D. (2009). Psychiatric disability in the community: Surveying the social landscape in the postdeinstitutional era [Doctoral dissertation, Umeå University]. UmU Print Service.

Slade, M. (2009). The contribution of mental health services to recovery. Journal of Mental Health, 18(5), 367-371. https://doi.org/10.3109/09638230 903191256

Swedish Association of Local Authorities and Regions. (2016). Kommungruppsindelning 2017 [Municipality compilation 2017]. Advant produktionsbyrå.

Tjörnstrand, C., Eklund, M., Bejerholm, U., Argentzell, E., \& Brunt, D. (2020). A day in the life of people with severe mental illness living in supported housing. BMC Psychiatry, 20(1). https://doi.org/10.1186/ s12888-020-02896-3

Wolch, J., \& Philo, C. (2000). From distributions of deviance to definitions of difference: Past and future mental health geographies. Health \& Place, 6(3), 137-157. https://doi.org/10.1016/S1353-8292(00) 00019-8

Wolpert, J., Dear, M., \& Crawford, R. (1975). Satellite mental health facilities. Annals of the Association of American Geographers, 65(1), 24-33. https://doi. org/10.1111/j.1467-8306.1975.tb01015.x

Yin, R. K. (2014). Case study research: Design and methods. SAGE. 


\section{About the Authors}

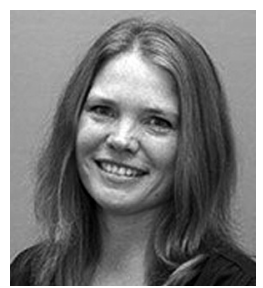

Maria Fjellfeldt is a Researcher and Senior Lecturer in Social Work at Dalarna University, Sweden. Her research concerns psychiatric disabilities and community-based support, from an individual as well as a societal perspective. Currently, she is engaged in research projects addressing cross-sectoral collaboration in planning for housing provision and living environments of people with mental ill-health, and promotion of mental health among children and adolescents in a complex organizational field.

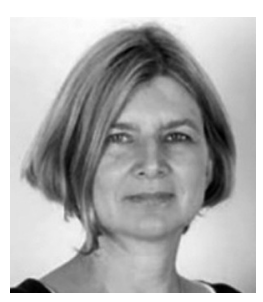

Ebba Högström is Researcher and Senior Lecturer at Spatial Planning at Blekinge Institute of Technology. Her research interest concerns social issues in urban planning and architecture, geographies of welfare, and experienced-based knowledge and methods. Currently, she is engaged in research projects addressing cross-sectoral collaboration in planning for housing provision and living environments of people with mental ill-health, and for age-friendly communities.

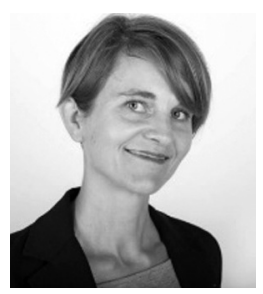

Lina Berglund-Snodgrass is a Researcher and Senior Lecturer in Spatial Planning at Blekinge Institute of Technology, Sweden. She is broadly interested in questions that address urban planning knowledge, ideas and forms of organising. She is currently engaged in a variety of research projects covering urban planning topics such as housing provision, urban experimentation and sustainable mobility.

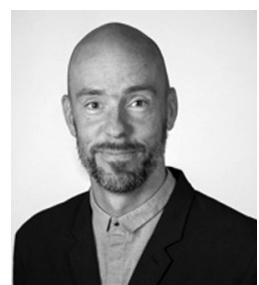

Urban Markström is a Professor in Social Work at Umeå University, Sweden. He also works as guest Professor at Helsinki University, Finland. His research concerns various aspects of community-based support for people with psychiatric disabilities. Among other things, he has conducted studies on policy development in the area, the implementation of reforms and specific psychosocial methods, attitudes to mental illness and strategies for increased user influence. 